\title{
Amplification of synoptic to annual variability of West African summer monsoon rainfall under global warming
}

\author{
Akintomide Afolayan Akinsanola $\mathbb{( D}^{1,2}$, Wen Zhou $\mathbb{D}^{2 凶}$, Tianjun Zhou (iD ${ }^{3}$ and Noel Keenlyside (iD ${ }^{4}$
}

Increased knowledge of future changes in rainfall variability is needed to reduce vulnerability to potential impacts of global warming, especially in highly vulnerable regions like West Africa. While changes in mean and extreme rainfall have been studied extensively, rainfall variability has received less attention, despite its importance. In this study, future changes in West African summer monsoon (WASM) rainfall variability were investigated using data from two regional climate models that participated in the Coordinated Regional Climate Downscaling Experiment (CORDEX). The daily rainfall data were band-pass filtered to isolate variability at a wide range of timescales. Under global warming, WASM rainfall variability is projected to increase by about $10-28 \%$ over the entire region and is remarkably robust over a wide range of timescales. We found that changes in mean rainfall significantly explain the majority of intermodel spread in projected WASM rainfall variability. The role of increased atmospheric moisture is examined by estimating the change due to an idealized local thermodynamic enhancement. Analysis reveals that increased atmospheric moisture with respect to warming following the Clausius-Clapeyron relationship can explain the majority of the projected changes in rainfall variability at all timescales.

npj Climate and Atmospheric Science (2020)3:21 ; https://doi.org/10.1038/s41612-020-0125-1

\section{INTRODUCTION}

Variability as used herein is essentially defined as the fluctuation of climate variables from the mean state, such as the deviation of temperature and precipitation at different timescales from the mean state. The West African region $\left(0-20^{\circ} \mathrm{N}, 20^{\circ} \mathrm{W}-20^{\circ} \mathrm{E}\right)$ has experienced large fluctuations in seasonal rainfall over the years ${ }^{1}$, with pronounced variability across a range of temporal scales. These range from synoptic and intraseasonal variations, which are critical for rain-fed agriculture, hydroelectric power generation, and water resource management ${ }^{2,3}$, to annual, interannual, and decadal variabilities that have important implications for long-term water availability. Notable is the persistent drought over the Sahel in the 1970s and 1980s, which is one of the strongest climate signals in recent observational records in global monsoon regions ${ }^{4,5}$.

The mean-state climate and associated variability have been substantially impacted by ongoing global warming under anthropogenic greenhouse gas (GHG) forcing. Knowing whether the West African summer monsoon (WASM) rainfall variability will amplify under global warming is crucial for mitigation and adaptation strategies for climate change. In fact, understanding the region's rainfall variability is particularly crucial for water resource planning to sustain agricultural, ecological, and water infrastructure development as well as hydroelectric power generation $^{6-9}$. For instance, increased rainfall variability can significantly reduce agricultural yields ${ }^{10,11}$, hinder the growth of children in developing countries ${ }^{12}$, and modulate extreme rainfall events, and thus it poses significant threats to the environment and society ${ }^{13}$. Some studies have reported that rainfall variability does not change much in a warming climate ${ }^{14,15}$, or that mean rainfall and its variability change at the same rate. While temperature variability does not change systematically in response to projections of global warming in most regions of the world ${ }^{16,17}$, it is not clear whether this holds true for rainfall.
Conventionally, the mean global rainfall in a warmer climate is expected to energetically increase by about $2-3 \% / K^{18,19}$, while changes in extreme rainfall are associated with near-surface moisture ${ }^{20}$. Rainfall is regulated largely by thermodynamic and dynamic components. The atmospheric water vapour concentration (i.e., thermodynamic component) is expected to increase following the Clausius-Clapeyron relationship by about $6-7 \%$ / $\mathrm{K}^{19,21}$. Increasing atmospheric moisture content implies enhancement of rainfall minus evaporation ${ }^{22}$ and thus is a manifestation of the "rich-get-richer" phenomenon. To put it simply, rainfall increases in climatological convergence regions and decreases in climatological subsidence regions ${ }^{19,23,24}$. The dynamic modulation of rainfall variability originates from changes in the variability of atmospheric circulation; therefore, it has been hypothesized that weakened or enhanced circulation variability could weaken or enhance rainfall variability, especially at interannual timescales ${ }^{25}$.

Currently, we lack a complete understanding of how rainfall will vary with respect to warming ${ }^{26-28}$; however, existing studies have shown that daily to interannual rainfall variability will increase in response to a doubling of carbon dioxide ${ }^{29,30}$, based on climate model simulations. More recent studies ${ }^{31-33}$ reported increased variability of rainfall at interannual and decadal timescales. Similarly, the interannual variability of precipitation is reported to generally amplify ${ }^{25}$, but its spatial pattern is complicated. Regional assessments, especially over the tropics where this study is focused, have reported a spatial shift in the position of actively convective regions ${ }^{34}$, enhancement of extreme rainfall ${ }^{35,36}$, increases in the daily to decadal variability of Asian-Australian monsoon rainfall ${ }^{37}$, and an increase in the interannual variability of Indian monsoon rainfall ${ }^{38}$. Studies focused on the variability of West African summer monsoon rainfall in a warmer climate are rare, even though this region has experienced substantial changes and variability in rainfall during the past century at different

\footnotetext{
Department of Geography, University of Georgia, Athens, GA, USA. ${ }^{2}$ Guy Carpenter Asia-Pacific Climate Impact Centre, School of Energy and Environment, City University of Hong Kong, Kowloon Tong, Hong Kong, China. ${ }^{3}$ LASG, Institute of Atmospheric Physics, Chinese Academy of Sciences, and University of Chinese Academy of Sciences, Beijing, China. ${ }^{4}$ Geophysical Institute, University of Bergen, and Bjerknes Centre for Climate Research, Bergen, Norway. ${ }^{\circledR}$ email: wenzhou@cityu.edu.hk
} 
A.A. Akinsanola et al.

Table 1. List of climate extreme indices of ETCCDI used in this study.

\begin{tabular}{llll}
\hline S/N & Extreme indices & Name & Definition \\
\hline 1 & CDD & Consecutive dry days & Maximum number of consecutive days with RR <1.0mm $\quad$ days/year \\
2 & RX5day & Maximum consecutive 5-day rainfall & Maximum consecutive 5-day rainfall \\
3 & R95pTOT & Very wet days & Total rainfall when RR $>95$ th percentile \\
\hline
\end{tabular}

timescales. Assessing how West African summer monsoon rainfall will vary from synoptic to annual timescales will give an overall picture of changes occurring in rainfall and thus improve the robustness of mitigation and adaptation strategies. In this study, we assess changes in summer monsoon rainfall variability across a range of timescales and present projections for the end of the 21st century over West Africa. The projections of JJAS rainfall variability are performed from synoptic to annual timescales using bandpass filtering to separate it from its original daily values. We study the global-warming-induced changes in summer monsoon rainfall variability using data from two CORDEX regional climate models.

\section{RESULTS}

Evaluation of simulated mean and extreme rainfall

Before assessing the ability of the CORDEX RCMs to reproduce the historical WASM rainfall variability and investigate the potential impacts of climate change on rainfall variability, we first examine the models' ability to reproduce the climatology of mean precipitation and three extreme rainfall indices described in Table 1. The spatial distribution of the mean JJAS rainfall, consecutive dry days (CDD), maximum consecutive 5-day rainfall (RX5day), and very wet day precipitation (R95pTOT) is presented in Fig. 1 for GPCP and TRMM observations, and for EnsMean. The results for each of the ensemble members are presented in Supplementary Figs. 2-5, respectively. The stippling in the figures represents grids where there is added value in the extreme rainfall indices from the RCMs compared to the indices from the driving GCMs. The GPCP and TRMM observations (Fig. 1a, b) exhibit two maximum rainfall centers located within the Guinea coast subregion of West Africa: the first is located around the Cameroonian highlands at about $4^{\circ}-10^{\circ} \mathrm{N}, 5^{\circ}-12^{\circ} \mathrm{E}$, while the second can be seen over the western portion, within the vicinity of the Fouta Djallon highlands $\left(5^{\circ}-12^{\circ} \mathrm{N}, 6^{\circ}-16^{\circ} \mathrm{W}\right)$. The rainfall zone over West Africa lies between $4^{\circ}$ and $15^{\circ} \mathrm{N}$, with rainfall decreasing from the Guinea coast to the Sahel subregion. Also, regions of maximum rainfall coincide with areas of high topography. EnsMean (Fig. 1c) realistically reproduces the spatial distribution of WASM rainfall. Similarly, all ensemble members (Supplementary Fig. 2a-h) skillfully reproduce the observed rainfall distribution and have pattern correlation coefficients (PCCs) greater than 0.80 when compared with the two observation products. Nonetheless, noticeable bias still exists among the RCMs; this has been described extensively in (ref. ${ }^{3}$ ) and is consistent with the findings in (ref. ${ }^{39}$ ). For the analysis of CDD (Fig. $1 \mathrm{~d}-\mathrm{f}$, and Supplementary Fig. 3), a rainfall threshold of below $1 \mathrm{~mm}$ has been assumed following (ref. ${ }^{3}$ ) in order to distinguish between wet and dry days. The two gridded observations (Fig. 1d, e) exhibit the maximum number of dry days over the southern boundary of the Sahel subregion, while the values grow southward over the Guinea coast. Overall, the RCM members (Supplementary Fig. 3) and their EnsMean (Fig. 1f) realistically reproduce the CDD, and the PCC exceeds 0.9 in all model members. Noticeable also is that the RCMs add remarkable value over several grids within the region.

Furthermore, the RCM members alongside their EnsMean realistically reproduce the spatial distribution of the maximum 5day rainfall (Fig. 1g-i and Supplementary Fig. 4) and very wet days (Fig. $1 \mathrm{j}-\mathrm{I}$ and Supplementary Fig. 5). We found that the RCA4
(CCLM) simulated extremes are closer to GPCP (TRMM) observations and that the mean precipitation and extreme precipitation indices are generally better represented in RCA4 than in CCLM, with noticeable biases over some grids. Additionally, EnsMean slightly outperforms individual models as a result of the cancellation of spatial errors.

Evaluation and projected changes in rainfall variability

Before presenting the results of the band-pass filtered analysis, we examine the climatology and projected changes in the unfiltered daily JJAS rainfall variability in the CORDEX models. The daily rainfall values presented herein are from the 50-year daily climatology, as described in the methodology. The EnsMean daily variability for JJAS in the historical simulations (1956-2005) is evaluated with Obs, and the results are presented in Fig. 2a, b. As is evident in Fig. 2a, the West African region exhibits high daily rainfall variability with maximum centres located over the Guinea coast subregion, especially around the Fouta Djallon highlands and coastal Nigeria. These regions of high rainfall variability are also notable for high and intense daily rainfall amounts ${ }^{3}$. Also, high variability in summer monsoon rainfall $(\sim 10 \mathrm{~mm} /$ day $)$ is noticeable over the central-eastern Sahel. EnsMean (Fig. 2b) realistically reproduces the observed rainfall variability although with higher magnitude when compared with Obs, especially over the major highlands and coastal Nigeria.

The changes in daily variability from the historical period to the RCP4.5 and RCP8.5 future period (2050-2099) are shown in Fig. 2c, d. Under global warming, EnsMean projects an increase in daily rainfall variability over most of West Africa, in the range of $10-28 \%$. The sign of the projected changes remains the same for both the RCP4.5 and RCP8.5 scenarios, but the magnitude of the changes and their spatial extent are greater in RCP8.5. Relative to the projected changes in EnsMean, considerable intermodel agreement is observed among the ensemble members, as at least $70 \%$ of the models agree on the sign of the change at most grid points over West Africa, thus depicting the robustness of the projected changes.

Projected changes in rainfall variability versus changes in mean climate

Changes in extreme events are affected by changes in both the mean and the variability; the most important of the two depends partly on their relative magnitude ${ }^{40}$. Using Eq. 2, we further assess the changes in CVP from the historical period to the RCP4.5 and RCP8.5 future period (2050-2099), shown in Supplementary Fig. 9. Similar to the projected changes based on standard deviation, EnsMean projects an increase in daily CVP over most of West Africa in the range of $5-80 \%$, with the highest values occurring where $\Delta \mathrm{Pr}$ approaches zero, in the Sahel subregion (Fig. $5 \mathrm{a}, \mathrm{b}$ ). It noteworthy that fewer grids over the highlands of the Guinea coast exhibit a decrease of around 5\%. Overall, the sign of the projected changes remains the same for both the RCP4.5 and RCP8.5 scenarios, but the magnitude of the changes is greater in RCP8.5. Considerable intermodel agreement is observed among the ensemble members, as at least $70 \%$ of the models agree on the sign of the change at most grid points.

Using Eq. 4, Fig. 2c, d is further decomposed into Fig. 2e-h. The projected increase in rainfall variability due to the change in mean 
(a) GPCP (Pr)

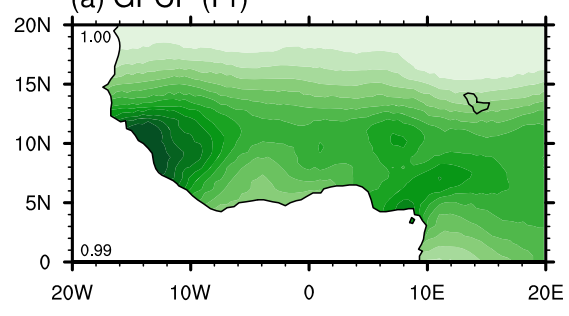

(b) TRMM (Pr)

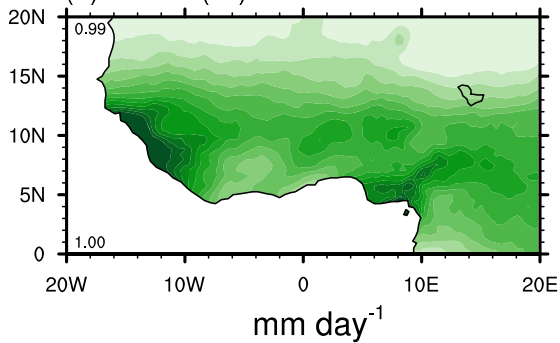

(c) EnsMean $(\mathrm{Pr})$

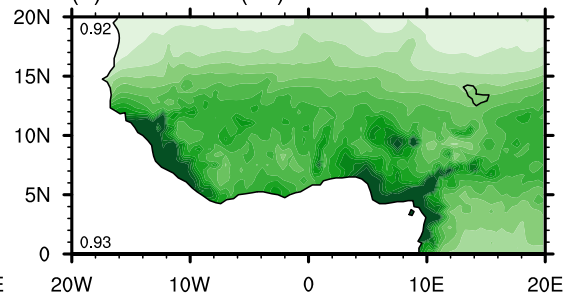

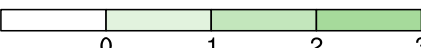

\begin{tabular}{ll|l|l|l|l} 
& & & & & $\mid$ \\
3 & 4 & 5 & 6 & 7
\end{tabular}

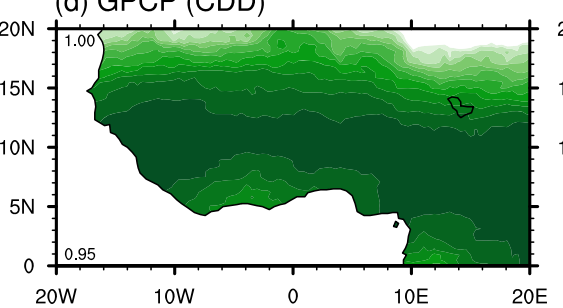

(e) TRMM (CDD)

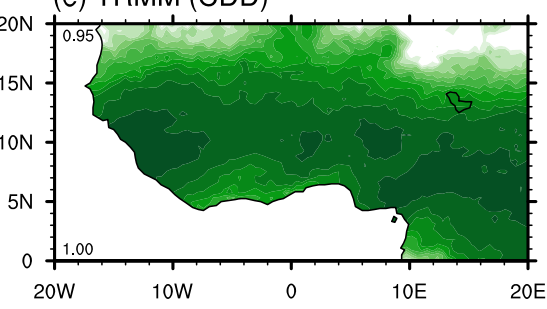

(f) EnsMean (CDD)

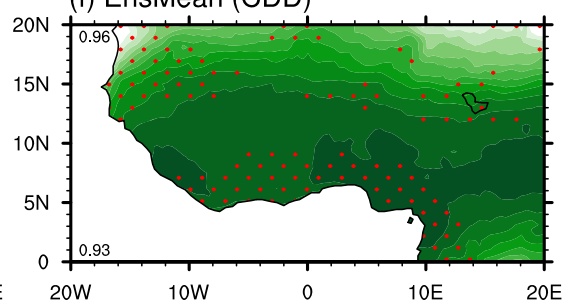

days year ${ }^{-1}$

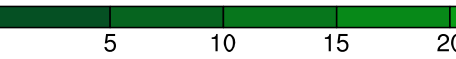

$\begin{array}{llll}1 & & & \\ 20 & 25 & 30 & 35\end{array}$

(h) TRMM (RX5day)
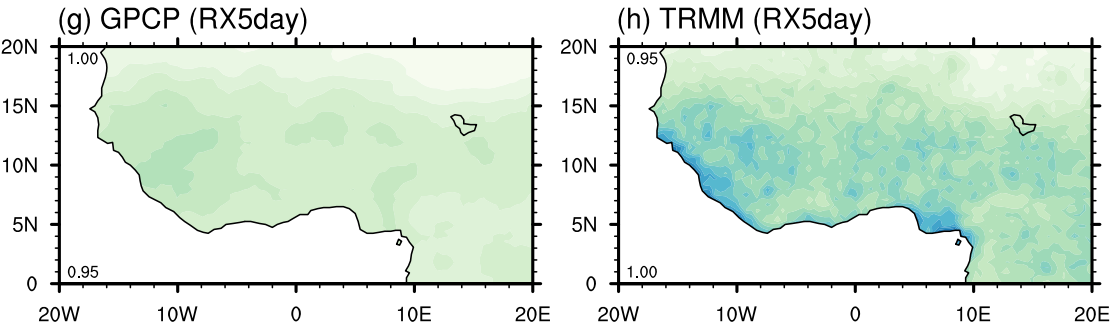

$\mathrm{mm}$ year $^{-1}$

\begin{tabular}{|c|c|c|c|c|c|c|c|c|c|}
\hline & & & & & & & & & \\
\hline 10 & 20 & 30 & 40 & 50 & 60 & 70 & 80 & 90 & 100
\end{tabular}

(j) GPCP (R95pTOT)
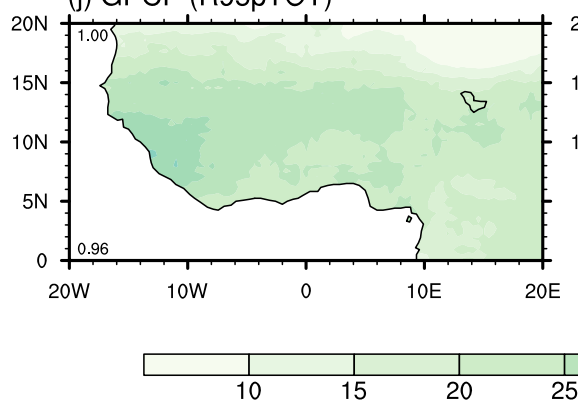

(k) TRMM (R95pTOT)

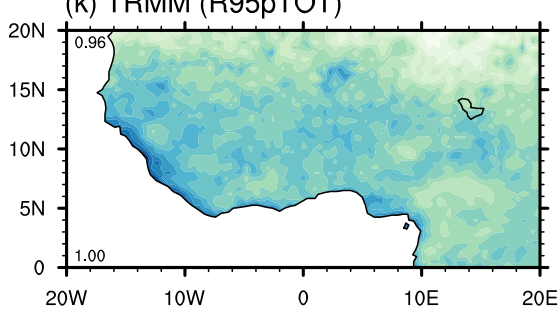

$\mathrm{mm}_{\text {year }}{ }^{-1}$

$\frac{1}{45}$

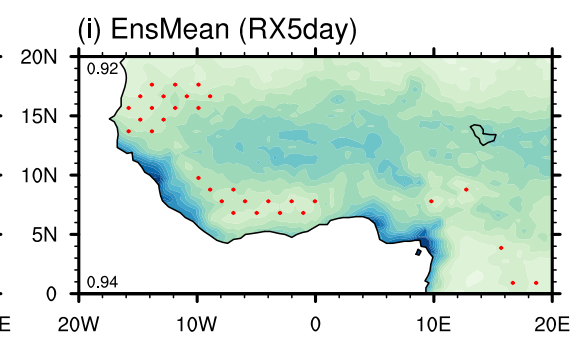

(i) EnsMean (RX5day)

Fig. 1 Present-day simulated mean and extreme rainfall. Spatial pattern of mean precipitation (Pr), consecutive dry days (CDD), maximum consecutive 5-day rainfall (RX5day), and very wet days (R95pTOT) for the period 1998-2005 for (a, d, g, j) GPCP, (b, e, h, k) TRMM, and (c, f, i, I)

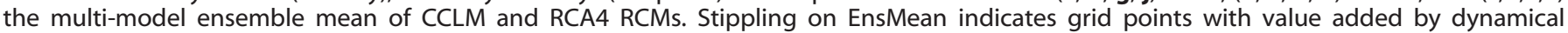
downscaling. The top left number is the PCC with GPCP and the bottom left with TRMM.

rainfall $\left(\triangle \mathrm{SDP}_{1}\right.$, Fig. $\left.2 \mathrm{e}, \mathrm{f}\right)$ is located mainly over the western half of the Guinea coast subregion, and some parts of the Cameroonian highlands where $\Delta P r$ is largest (Fig. 5a, b). High negative values in $\triangle \mathrm{SDP}_{1}$ can be found over the western parts of the Sahel subregion, around Senegal where $\Delta \mathrm{Pr}<0$. The magnitude of the changes and their spatial extent are greater in RCP8.5, but the sign of the projected changes remains the same for both RCPs. Furthermore, the projected changes in rainfall variability that are due to the change in CVP $\left(\triangle \mathrm{SDP}_{2}\right.$, Fig. $\left.2 \mathrm{~g}, \mathrm{~h}\right)$ dominate the earlier reported future increase in rainfall variability in Fig. 2c, d. Most of the grid points over West Africa exhibit an increasing variability, which is dominated by the changes in CVP. The sign of $\Delta \mathrm{SDP}_{2}$ is similar in both the RCP4.5 and RCP8.5 scenarios, but the magnitude of the change is greater in RCP8.5. Overall, considerable intermodel agreement is observed among the ensemble members, as at least $70 \%$ of the models agree on the sign of the change at most grid points over West Africa.

Regional changes in rainfall variability and the role of the thermodynamic factor

Furthermore, a detailed analysis of the full model spread is extended over individual subregions of West Africa to explore whether a similar increase would occur over a range of timescales. 
(a) Obs SDP

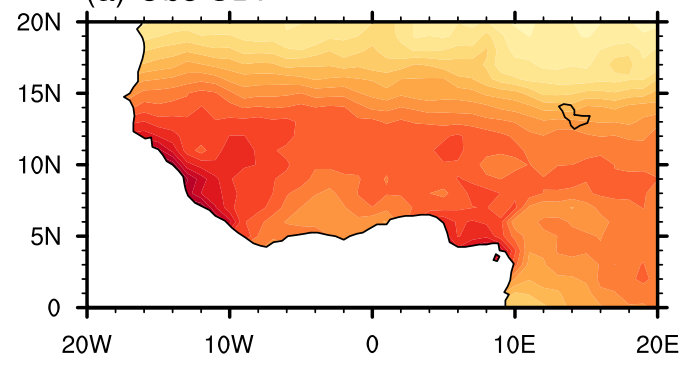

(b) EnsMean SDP

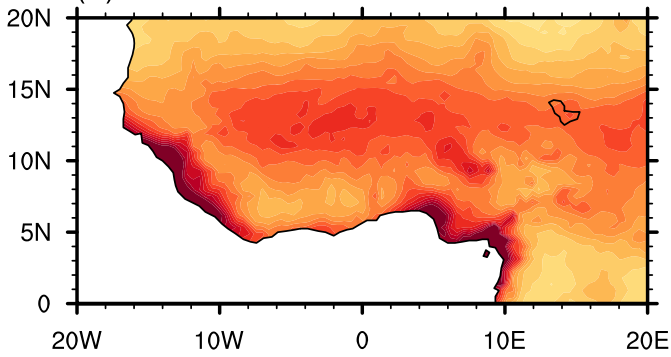

$\mathrm{mm} \mathrm{day}^{-1}$

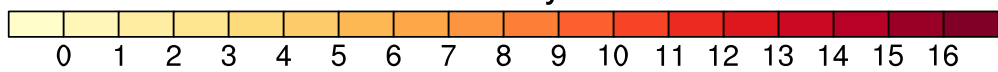

(c) EnsMean $\Delta \mathrm{SDP}$ (RCP4.5)

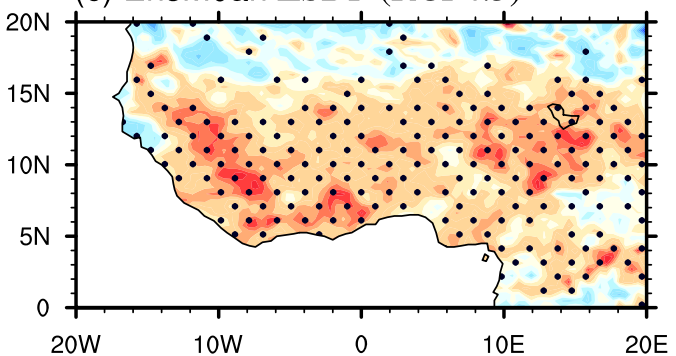

(d) EnsMean $\triangle \mathrm{SDP}$ (RCP8.5)

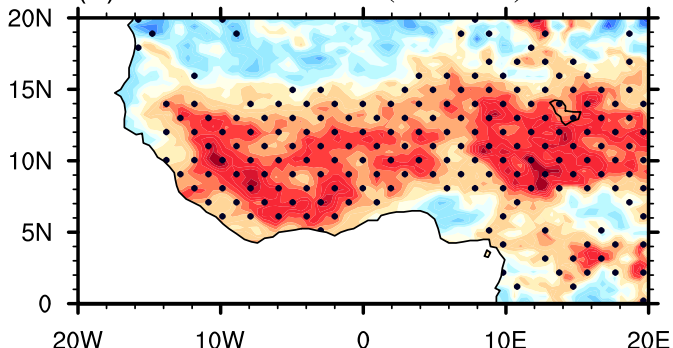

(e) EnsMean $\triangle$ SDP1 (RCP4.5)

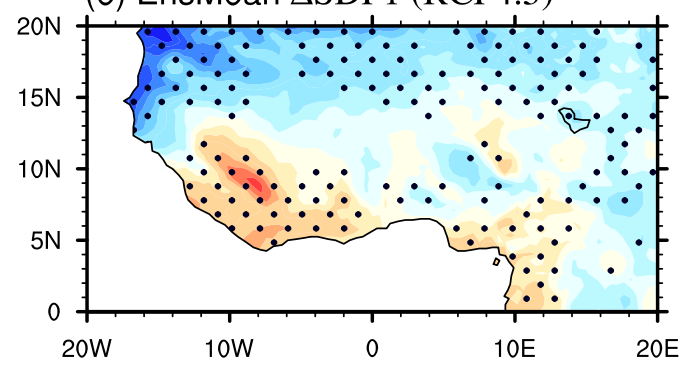

(f) EnsMean $\triangle$ SDP1 (RCP8.5)

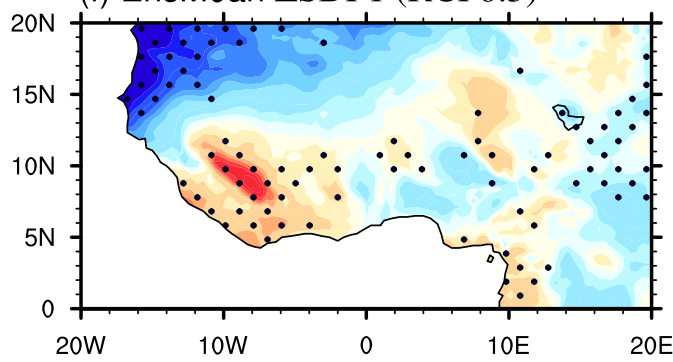

(g) EnsMean $\triangle$ SDP2 (RCP4.5)

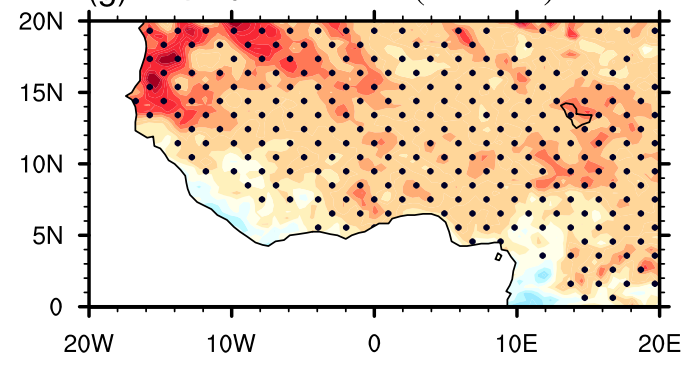

(h) EnsMean $\triangle$ SDP2 (RCP8.5)

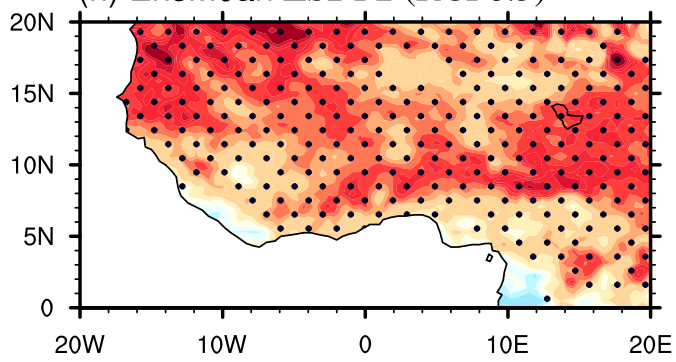

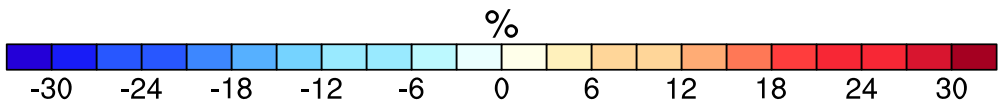

Fig. 2 Historical and future changes in rainfall variability. Spatial pattern of Obs [average of GPCP and TRMM observations] and multimodel ensemble mean standard deviation of daily JJAS rainfall anomalies ( $\mathrm{mm}$ day ${ }^{-1}$ ) in historical simulations $(\mathbf{a}, \mathbf{b})$, and change in standard deviation of daily JJAS rainfall anomalies (\%) from historical (1956-2005) to future (2050-2099) for (c, e, f) RCP4.5 and (d, f, h) RCP8.5. $\Delta$ SDP1 is the part of the change in the standard deviation of precipitation ( $\triangle$ SDP) explained entirely by the change in mean rainfall, and $\triangle$ SDP2 is the part associated with the change in the coefficient of variation. Stippling indicates grid points where at least $70 \%$ of the RCMs agree on the sign of the change in EnsMean. 

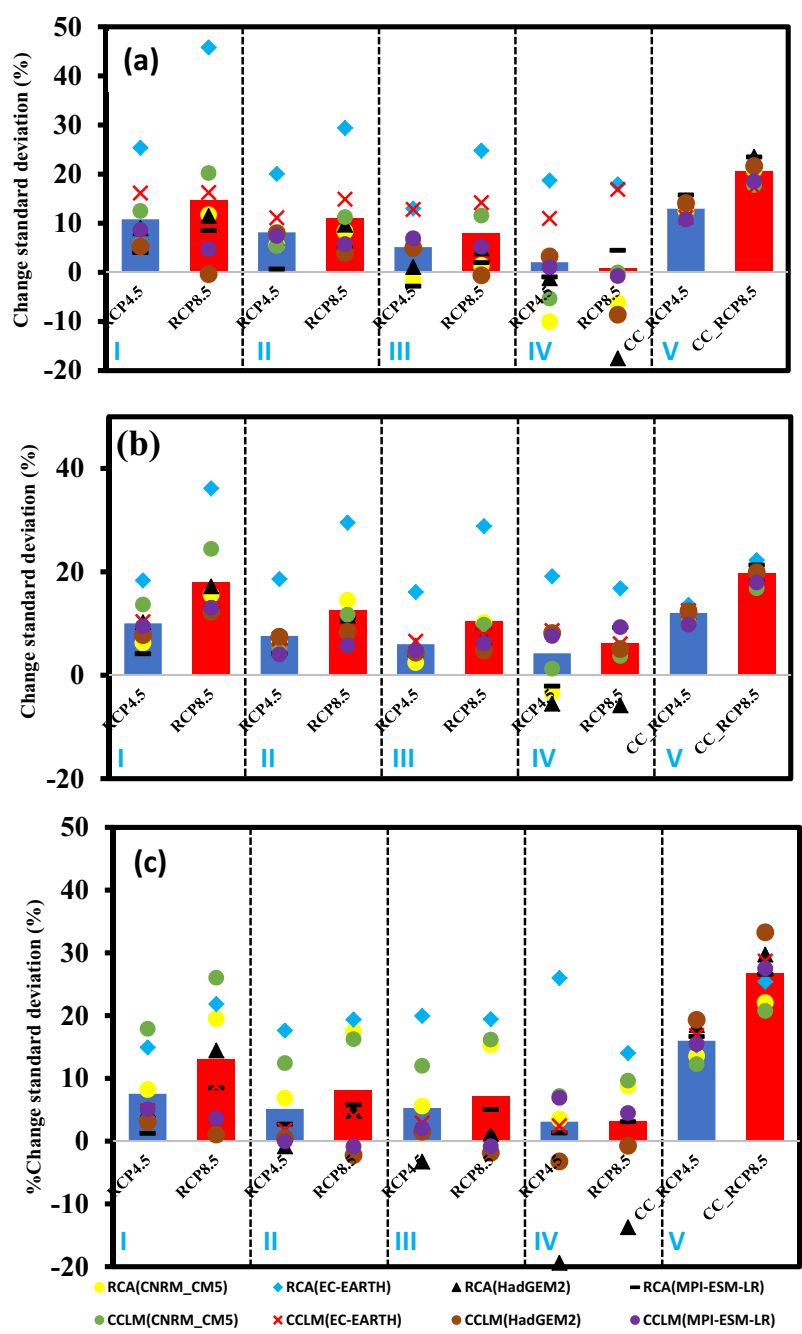

Fig. 3 Regional changes in rainfall variability and the role of thermodynamic factor. Future time slice (2050-2099) minus historical time slice (1956-2005) differences in band-pass filtered daily rainfall standard deviation (\%) for the (I) synoptic, (II) monthly, (III) intraseasonal, and (IV) annual timescales over the (a) Guinea coast, (b) Savannah, and (c) Sahel. (V) The idealized thermodynamically enhanced CC. Bars representing EnsMean for RCP4.5 (RCP8.5) are in blue (red).

The percentage change in daily rainfall variability at different timescales over West African subregions is presented in Fig. 3. EnsMean projects a consistent increase in daily rainfall variability across all timescales and all West African subregions. There is also a striking level of consistency, as depicted by considerable model agreement across all timescales and subregions. The largest increase in future rainfall variability within the subregions can be observed at the synoptic to intraseasonal timescales, although obvious intermodel spread still exists, especially at the annual scale.

Previous studies have reported that increased rainfall variability may be due to the higher atmospheric moisture content in a warmer climate, following the Clausius-Clapeyron relation ${ }^{19,21,37}$. A "null hypothesis" of direct relevance here is that increased monsoon rainfall variability may be a result of higher atmospheric moisture content in a warmer climate. In fact, increased atmospheric moisture has been previously reported in climate change projections over West Africa ${ }^{41}$. We therefore calculate an idealized enhancement of the daily monsoon rainfall, as outlined in the methodology section. The difference between the "CC" change in rainfall variability for RCP4.5 and RCP8.5 is compared with the changes in rainfall variability, indicating how much of the simulated change under the two RCPs may be due to this thermodynamic increase in atmospheric moisture. For all West African subregions (Label $\mathbf{V}$ in Fig. 3a-c), most of the models alongside their EnsMean simulate smaller changes in rainfall variability than expected from the idealized thermodynamic response at all timescales, indicating that the thermodynamic contribution may be the dominant factor in the projected rainfall variability over West Africa.

The change in rainfall variability is not significantly correlated with the strength of HIST rainfall variability over any of the West African subregions or at any timescale except the intraseasonal timescale over the Guinea coast subregion and for the RCP4.5 scenario (Supplementary Fig. 10), where correlations are positive and significant at the $95 \%$ level. The lack of significant positive correlations at any timescale implies that the model spread in rainfall variability change is not due to the intermodel spread in HIST rainfall variability. Nevertheless, changes in rainfall variability are significantly positively correlated with changes in mean monsoonal rainfall for each subregion at most timescales (Fig. 4). This strong statistically significant relationship implies that the change in mean rainfall explains certain parts of the intermodel spread in changes in rainfall variability.

Projected changes in mean and extreme rainfall

The fact that the examined CORDEX RCM simulations exhibit a robust future increase in summer monsoon rainfall variability at the majority of timescales motivates us to further investigate the changes in mean and extreme rainfall indices. The spatial response of summer monsoon mean rainfall, CDD, RX5day, and R95pTOT to global warming is presented in Fig. 5 by comparing the twenty-first century future time slice $(2050-2099)$ to the historical period (1956-2005) under the RCP4.5 and RCP8.5 scenarios. In general, future enhancement of summer monsoon rainfall variability over West Africa is associated with an increase in mean rainfall of about 4-14\% over the Guinea coast subregion (Fig. 5a, b). A slight zonal dipole is evident over the Sahel subregion with a decrease (increase) over the western (eastern) Sahel subregion, which is particularly obvious in RCP8.5. Only the decreasing mean rainfall over the western Sahel in evident in RCP4.5. Our result is consistent with previous studies ${ }^{42-45}$ that reported future zonal dipole changes in mean rainfall over West Africa. Enhancement (reduction) in consecutive dry days is evident over the Sahel (part of the Guinea coast). Also, both the maximum 5-day rainfall and extreme wet day precipitation exhibit a future increase of about $10-25 \%$. The projected changes presented herein are considerably robust for mean precipitation and R95pTOT, as at least $70 \%$ of the RCM members agree on the sign of the change at most grid points. High intermodel spread is evident for changes in CDD and RX5day, as there are fewer grid points with at least $70 \%$ model agreement. Also, the magnitudes of the projected increases and decreases are greater under RCP8.5, which may be a result of its stronger forcing, as previously noted ${ }^{3}$. Overall, the future increase in summer monsoon rainfall variability over West Africa is associated with increasing consecutive dry days and extreme rainfall, and could have strong implications for future water resources, agriculture, hydroelectric power generation, and social stability of the region.

\section{DISCUSSION}

Understanding changes in rainfall variability is important for a complete explanation of the response of the hydrological cycle to global warming and its impacts. In this study, changes in summer monsoon rainfall variability over West Africa in the historical and future climate (RCP4.5 and RCP8.5) were investigated at a wide range of timescales from synoptic to annual. We used band-pass filtering to isolate the variability at each timescale, and the range 

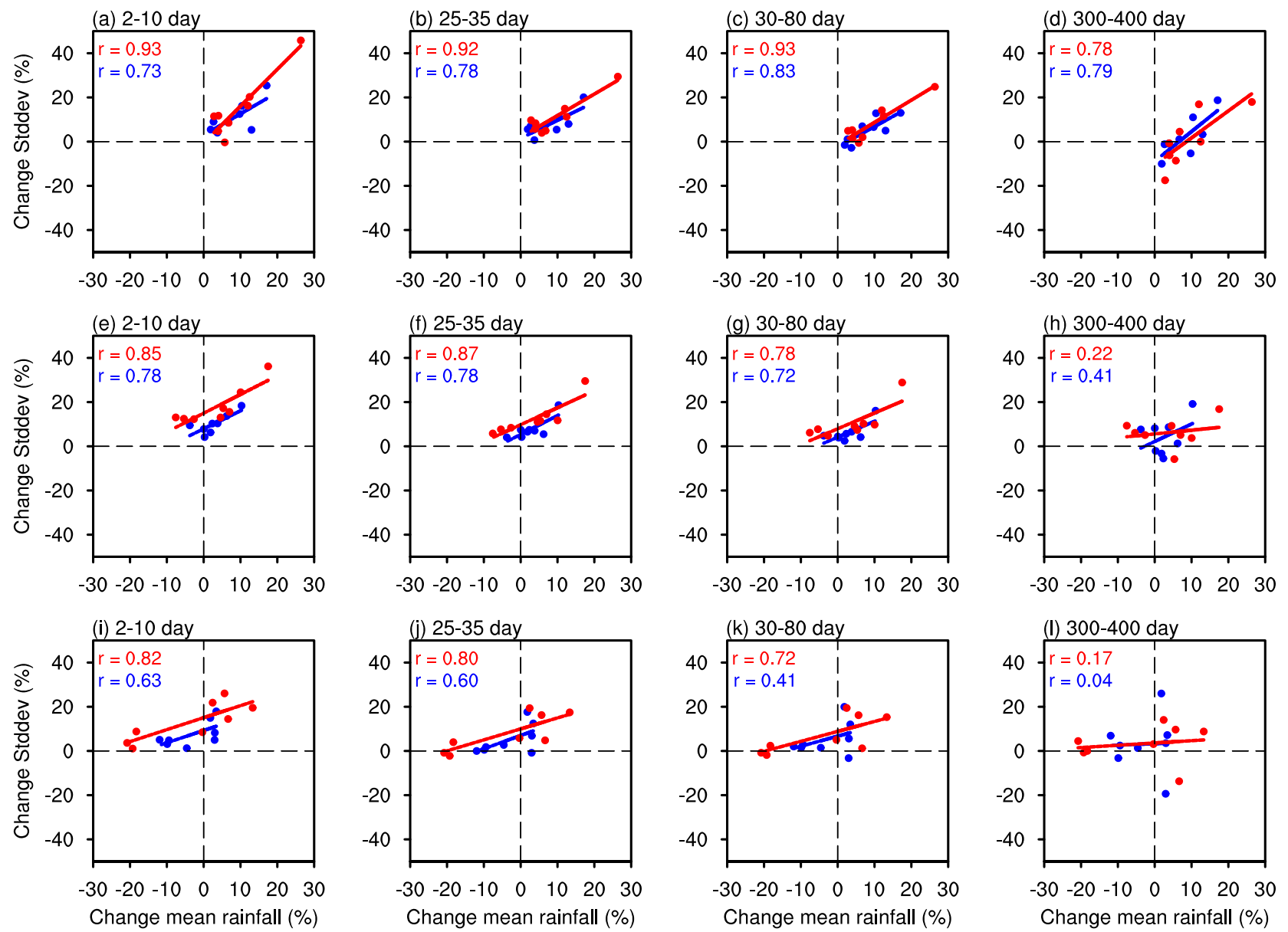

Fig. 4 Relationship between change in mean rainfall and change in rainfall variability. Change in mean JJAS rainfall (\%) versus change in JJAS rainfall variability from HIST (1956-2005) to RCP4.5 and RCP8.5 (2050-2099) (\%) for the (a, e, i) synoptic, (b, f, j) monthly, (c, g, k) intraseasonal, and (d, h, I) annual timescales. Blue (red) for RCP4.5 (RCP8.5) overall of the West African subregion for the Guinea coast (a-d), Savannah (e-h), and Sahel (i-I).

of model rainfall standard deviations was calculated for the historical climate (1956-2005) and future climate (2050-2099) under the RCP4.5 and RCP8.5 scenarios. Results show that daily rainfall variability is expected to increase in the future over most of West Africa, and this future increase is largely due to changes in the coefficient of variation and partly due to changes in mean rainfall. A profound future increase in rainfall variability of about $10-28 \%$ is also evident at most timescales and overall subregions. For longer timescales, particularly annual, a slight intermodel spread can be observed, thus implying uncertainty in the projections. The changes in rainfall variability are not significantly correlated with the strength of HIST rainfall variability at most timescales or in any of the West African subregions. However, changes in rainfall variability are significantly positively correlated with changes in mean JJAS rainfall for each subregion at most timescales. Furthermore, the projected increase in rainfall variability is associated with a future increase in mean rainfall over the Guinea coast subregion alongside increasing extreme rainfall over West Africa.

Most of the models alongside their EnsMean simulate smaller changes in rainfall variability than expected from the idealized local thermodynamic response at all timescales, indicating that the thermodynamic contribution may be the dominant factor in the projected rainfall variability over West Africa. We expect little or no contribution from the dynamic changes. In fact, a previous study has reported weakening of the West African summer monsoon circulation, partly due to the weakening of the Tropical
Easterly $\mathrm{Jet}^{41}$. We found that the use of EnsMean effectively minimizes the uncertainty in our results, and our findings of overall consistency in the sign of the changes in rainfall variability and associated extremes can be used as a scientific basis for regional development and adaptation strategies in West Africa. Overall, the projected increase in summer monsoon rainfall variability should have significant impacts on agricultural productivity and water resource management over the region. Therefore, it is crucial for West African countries to seriously consider implementing adaptation strategies and mitigation measures to combat the potential impacts of future changes.

\section{METHODS}

Daily rainfall data from two regional climate model (RCM) simulations that were available at the time of the analysis in the CORDEX project are analysed. The Rossby Center (SMHI) RCM (RCA4; ref. ${ }^{46}$ ) and the Consortium for Small-scale Modelling (COSMO) RCM (CCLM; ref. ${ }^{47}$ ) are used to downscale four Coupled Model Intercomparison Project Phase 5 (CMIP5) GCMs (CNRM-CM5, EC-EARTH, HadGEM2-ES, and MPI-ESM-LR). These models have been used in previous studies owing to their remarkably good performance ${ }^{3,48}$. All model outputs are analysed with the original grid resolution of $0.44^{\circ} \times 0.44^{\circ}(\sim 50 \mathrm{~km})$ and integrated over the West African domain and its subregions (see Supplementary Fig. 1 ) as defined in ref. ${ }^{3}$. The CMIP5 GCM projections are forced by the Representative Concentration Pathways (RCPs) as described in refs. ${ }^{49,50}$. Analysis was performed for the historical climate (HIST, 1956-2005) and future climate (2050-2099) under the intermediate and high emission pathways, RCP4.5 and RCP8.5, respectively. Due to the scarcity of rain-gauge data over West 
(a) $\operatorname{RCA} 4.5(\Delta \operatorname{Pr})$

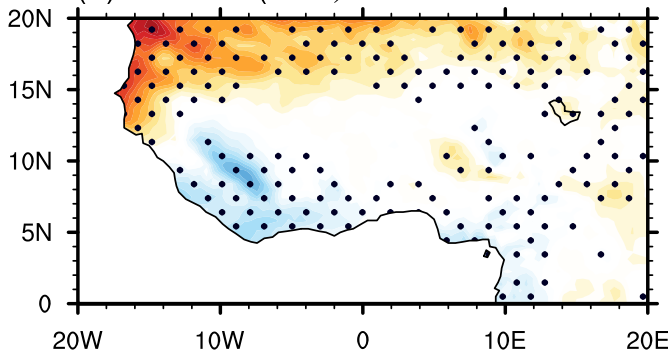

(b) RCP8.5 ( $\triangle \operatorname{Pr})$

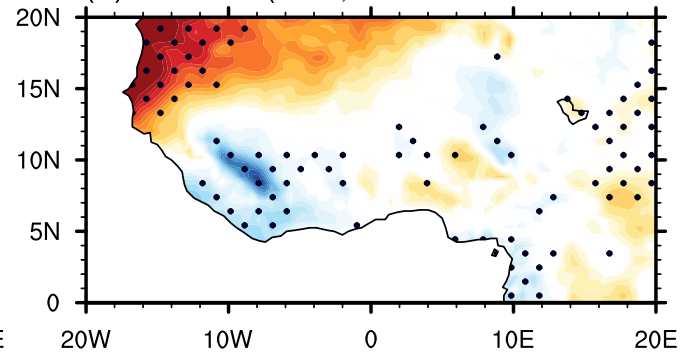

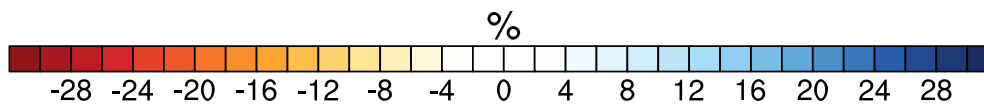

(c) RCA4.5 ( $\triangle \mathrm{CDD})$

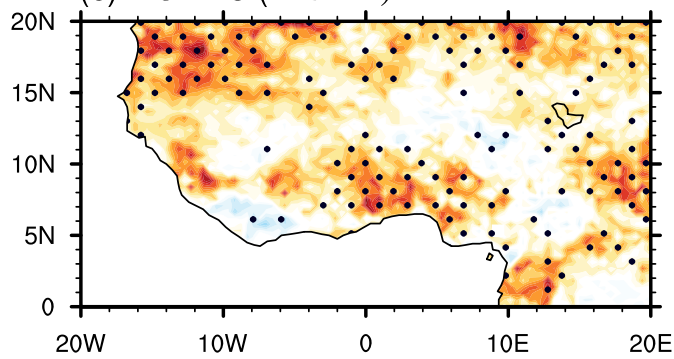

(d) RCP8.5 ( $\triangle \mathrm{CDD})$

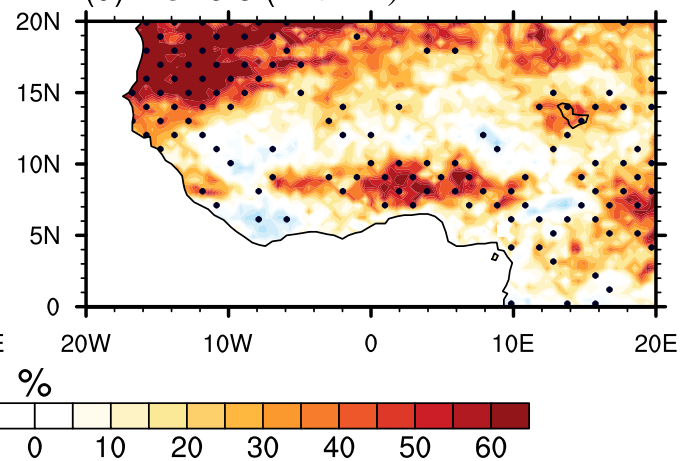

(e) RCA4.5 ( $\Delta$ Rx5day)

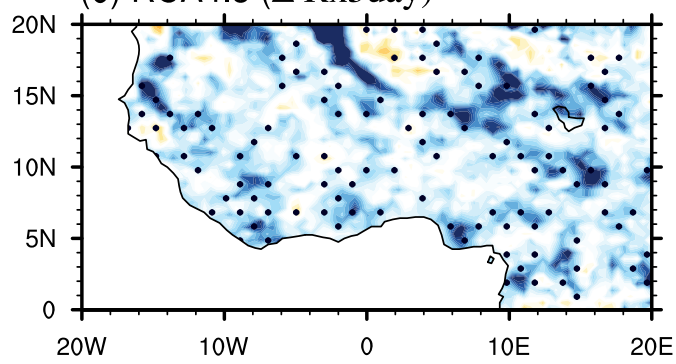

(f) RCP8.5 ( $\Delta$ Rx5day)

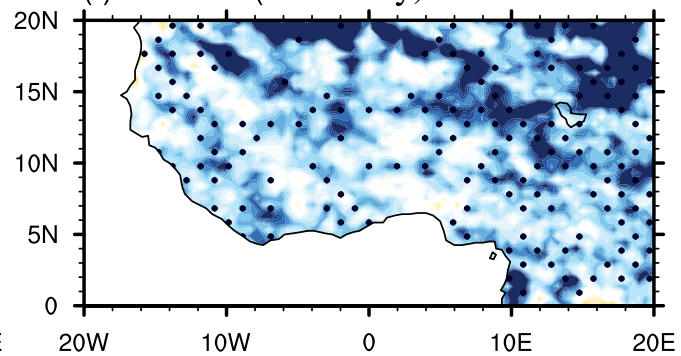

(g) RCA4.5 ( $\triangle$ R95pTOT)

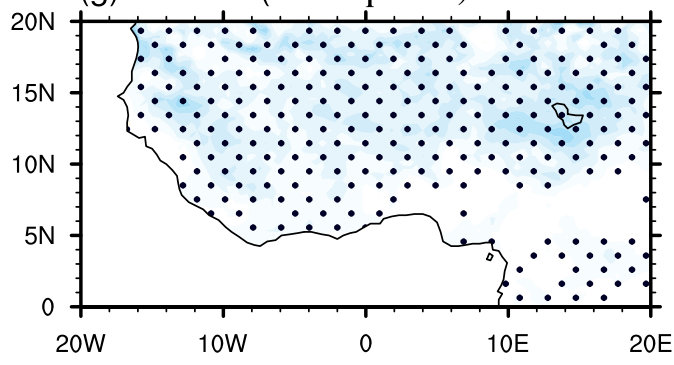

(h) RCP8.5 ( $\Delta$ R95pTOT)

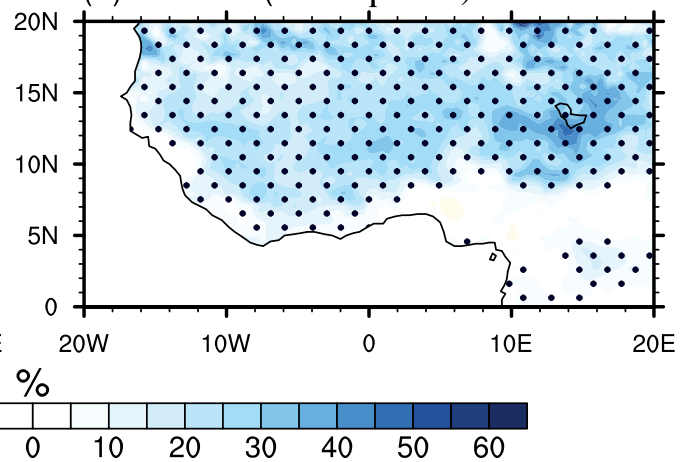

Fig. 5 Future changes in mean and extreme rainfall. Change Projected multi-model changes in (a, b) daily precipitation, (c, d) consecutive dry days, $(\mathbf{e}, \mathbf{f})$ maximum 5 -day precipitation, and $(\mathbf{g}, \mathbf{h})$ total precipitation greater than or equal to the daily 95 th percentile, for RCP4.5 (a, $\mathbf{c}, \mathbf{e}$, g) and RCP8.5 (b, d, f, h). Stippling indicates grid points where at least 70\% of the RCMs agree on the sign of the change in EnsMean. 
Africa, we evaluated the model results by comparing them with two observation products over the shorter historical period of 1998-2013: (1) the Global Precipitation Climatology Project One-Degree Daily (GPCP 1DD Version 1.2; ref. ${ }^{51}$ ); and (2) the $0.25^{\circ}$ resolution Tropical Rainfall Measuring Mission (TRMM 3B43 version 7; ref. ${ }^{52}$ ). The GPCP and TRMM data have been used extensively over the region and are credited as a viable alternative for evaluating climate models ${ }^{8,53-55}$, although potential uncertainties may still exist due to uncertainties in the data sources and processing algorithms.

For a detailed evaluation of the RCMs' ability to reproduce the historical rainfall characteristics over West Africa, we first assess the capability of the CORDEXs RCMs to reproduce mean rainfall climatology and extreme rainfall indices. The three extreme rainfall indices that were evaluated are described in Table 1. These indices are based on the definitions recommended by the Expert Team on Climate Change Detection and Indices (ETCCDI) and are based on daily precipitation. They have been widely used in the detection, attribution, and projection of changes in climate extremes ${ }^{3,56}$. The evaluation of these extreme precipitation indices and mean rainfall is carried out by considering a common period across the observations and simulations (1998-2005). The ability of the RCMs to improve (or not) the driven GCM simulations in the present time period was assessed, using the added value approach adopted by ${ }^{3,57}$ and expressed in Eq. 1:

$$
\mathrm{AV}=\frac{\left(X_{\mathrm{GCM}}-X_{\mathrm{OBS}}\right)^{2}-\left(X_{\mathrm{RCM}}-X_{\mathrm{OBS}}\right)^{2}}{\operatorname{Max}\left(\left(X_{\mathrm{GCM}}-X_{\mathrm{OBS}}\right)^{2},\left(X_{\mathrm{RCM}}-X_{\mathrm{OBS}}\right)^{2}\right)}
$$

where $X_{G C M}, X_{O B S}$, and $X_{R C M}$ represent the index calculated from large-scale forcing (GCM), observations (GPCP), and RCMs. Defined in this way, the added value (AV), which is computed at each grid point, is positive where the RCM models' squared error is smaller than that of the corresponding GCM; that is, where the RCM models improve the GCMs' results. Normalization is introduced so that $-1 \leq \mathrm{AV} \leq 1$ (ref. ${ }^{57}$ ).

We quantify rainfall variability by its standard deviation, a descriptive statistic that can be used to describe spread or variability, as described in ref. ${ }^{38}$. First, the climatological annual cycle was removed at each model grid point by subtracting the 50 -year daily mean rainfall for each day, and the area-weighted averages were then computed over the West African domain. Furthermore, the area-averaged daily anomalies computed over the West African domain were detrended and band-pass filtered using the following bands: "synoptic" (2-10 days), "monthly" (25-35 days), "intraseasonal" (30-80 days), and "annual" (300-400 days), to isolate variability at these timescales following $\left(\right.$ ref. $^{37}$ ). The use of a 50 -year time slice of model output limits the assessment of decadal variability. (A further detailed explanation of the application of band-pass filtering to daily rainfall anomalies is presented in Supplementary Fig. 6 for Obs [average of GPCP and TRMM observations], and for one of the RCM members in Supplementary Fig. 7 as an example). Overall, the RCMs generally reproduce the observations, but we found that the RCA4 (CCLM) variability was closer to GPCP (TRMM) observations (this observation has been discussed in the results section). The filtered daily rainfall anomalies were extracted for the summer monsoon season (June-September, JJAS). The standard deviation of the filtered daily area-averaged JJAS rainfall anomalies was calculated for each model and timescale, and the difference between the historical and future (RCP4.5 and RCP8.5) rainfall standard deviations was determined. While daily rainfall has a highly skewed distribution, particularly at a station or grid point scale, this skewness is reduced when area-averaged data are used and when daily anomalies from the long-term daily climatology are calculated (see Supplementary Fig. 8).

As a further measure of precipitation variability, we use the coefficient of variation of precipitation (CVP) described in Eq. 2 (ref. ${ }^{58-60}$ )

$$
\mathrm{CVP}=\frac{\mathrm{SDP}}{\overline{P r}}
$$

where SDP is the standard deviation of precipitation, and $\bar{P} r$ is the mean precipitation. CVP may become problematic when $\bar{P} r$ approaches zero, especially north of $16^{\circ} \mathrm{N}$, which is outside our study domain, as noted in Supplementary Fig. 1.

On the other hand, one might argue that changes in the standard deviation of precipitation (SDP) are partly an expected consequence of changes in the mean ${ }^{31}$. Using the relationship in Eq. 3

$\mathrm{SDP}=\operatorname{Pr} \times \mathrm{CVP}$, the change in SDP can be written as

$$
\begin{aligned}
\Delta \mathrm{SDP} & =\left(\Delta P r \times \mathrm{CVP}_{\text {HIST }}\right)+\Delta \mathrm{CVP} \times\left(\operatorname{Pr}_{\text {HIST }}+\Delta P r\right) \\
& =\Delta \mathrm{SDP}_{1}+\Delta \mathrm{SDP}_{2}
\end{aligned}
$$

where $P r_{\text {HIST }}$ and CVP $\mathrm{P}_{\text {HIST }}$ are the HIST precipitation and CVP, respectively, and $\triangle C V P$ and $\triangle P r$ are the changes in CVP and precipitation, respectively. $\triangle S D P_{1}$ is the part of the SDP change that is explained entirely by the change in the mean precipitation, and $\triangle \mathrm{SDP}_{2}$ is the part associated with the change in the coefficient of variation. Equation 4 is very useful because it allows us to quantify the separate contributions of changes in mean precipitation and changes in CVP to the changes in precipitation variability.

To quantify the influence of thermodynamic increases on atmospheric moisture content, we used an idealized enhancement due to the Clausius-Clapeyron ("CC") relationship following (ref. ${ }^{61}$ ). The historical mean rainfall was multiplied by $7 \% \times \Delta T$, where $\Delta T$ is the change in annual mean temperature over West Africa for RCP4.5 and RCP8.5 (2050-2099) minus HIST (1956-2005) for each model. This results in a fractional change in rainfall variability $(7 \% \times \Delta T)$ for each model, which is the same in each time band. This " $C C$ " fractional change in rainfall variability can be compared with the fractional change from HIST to RCP4.5 and RCP8.5. Finally, the multi-model ensemble mean of both RCA- and CCLM-driven simulations (eight model members in total), referred to herein as "EnsMean," is used to reduce natural variability and systematic biases in the model members ${ }^{3}$.

\section{DATA AVAILABILITY}

The CORDEX dataset used in this study is from https://www.cordex.org/data-access/. The daily precipitation data from the Global Precipitation Climatology Project (GPCP) are from https://precip.gsfc.nasa.gov/, and that from the Tropical Rainfall Measuring Mission (TRMM) are from https://pmm.nasa.gov/data-access/downloads/trmm.

\section{CODE AVAILABILTY}

The data in this study were analyzed and the figures were created with NCAR Command Language ( $\mathrm{NCL}$; ref. ${ }^{62}$ ). All relevant codes used in this work are available, upon request, from the corresponding author.

Received: 16 August 2019; Accepted: 12 May 2020; Published online: 12 June 2020

\section{REFERENCES}

1. Nicholson, S. E. The West African Sahel: a review of recent studies on the rainfall regime and its interannual variability. ISRN Meteorol. 2013, 32 (2013).

2. Lebel, T., Diedhiou, A. \& Laurent, H. Seasonal cycle and inter-annual variability of the Sahelian rainfall at hydrological scales. J. Geophys. Res. 108, 8389 (2003).

3. Akinsanola, A. A. \& Zhou, W. Projections of West African summer monsoon rainfall extremes from two CORDEX models. Clim. Dyn. 52, 2017 (2019).

4. Ward, M. N. Diagnosis and short-lead time prediction of summer rainfall in tropical North Africa at interannual and multidecadal timescales. J. Clim. 11, 3167-3191 (1998).

5. Trenberth, K. E. et al. In Climate Change 2007: The Physical Science Basis. Contribution of Working Group I to the Fourth Assessment Report of the Intergovernmental Panel on Climate Change (eds. Solomon S. et al) (Cambridge University Press, Cambridge, 2007) pp. 235-336.

6. Akinsanola, A. A., Ogunjobi, K. O., Gbode, I. E. \& Ajayi V. O. Assessing the capabilities of three regional climate models over CORDEX Africa in simulating West African summer monsoon precipitation. Adv. Meteorol. https://doi.org/10.1155/ 2015/935431 (2015).

7. Akinsanola, A. A. et al. Evaluation of rainfall simulations over West Africa in dynamically downscaled CMIP5 global circulation models. Theor. Appl. Climatol. 132, 437 (2018).

8. Odoulami, R. C. \& Akinsanola, A. A. Recent assessment of West African summermonsoon daily rainfall trends. Weather 73, 283-287. https://doi.org/10.1002/ wea.2965 (2018).

9. Dunning, C. M. et al. Identification of deficiencies in seasonal rainfall simulated by CMIP5 climate models. Environ. Res. Lett. 12, 114001 (2017).

10. Rowhani, P., Lobell, D. B., Linderman, M. \& Ramankutty, N. Climate variability and crop production in Tanzania. Agric. Meteorol. 151, 449-460 (2011).

11. Gornall, J. et al. Implications of climate change for agricultural productivity in the early twenty-first century. Philos. Trans. R. Soc. Lond. Ser. B Biol. Sci. 365, 2973-2989 (2010). 
12. Shively, G. E. Infrastructure mitigates the sensitivity of child growth to local agriculture and rainfall in Nepal and Uganda. Proc. Natl Acad. Sci. USA 114, 903-908 (2017).

13. IPCC. In A Special Report of Working Groups I and II of the Intergovernmental Panel on Climate Change End Fragment (eds. Field C. B. et al.) (Cambridge University Press, Cambridge, 2012).

14. Hawkins, E. \& Sutton, R. The potential to narrow uncertainty in projections of regional precipitation change. Clim. Dyn. 37, 407-418 (2011).

15. Thompson, D. W. J., Barnes, E. A., Deser, C., Foust, W. E. \& Phillips, A. S. Quantifying the role of internal climate variability in future climate trends. J. Clim. 28, 6443-6456 (2015).

16. Huntingford, C., Jones, P. D., Livina, V. N., Lenton, T. M. \& Cox, P. M. No increase in global temperature variability despite changing regional patterns. Nature $\mathbf{5 0 0}$ 327-330 (2013).

17. Lehner, F., Deser, C. \& Sanderson, B. M. Future risk of record-breaking summer temperatures and its mitigation. Clim. Change. https://doi.org/10.1007/s10584016-1616-2 (2016).

18. Allen, M. R. \& Ingram, W. J. Constraints on future changes in climate and the hydrologic cycle. Nature 419, 224-232 (2002).

19. Held, I. M. \& Soden, B. J. Robust responses of the hydrologic cycle to global warming. J. Clim. 19, 5686-5699 (2006).

20. O'Gorman, P. A. \& Schneider, T. The physical basis for increases in precipitation extremes in simulations of 21 st-century climate change. Proc. Natl Acad. Sci. USA 106, 14773-14777 (2009).

21. Vecchi, G. A. et al. Weakening of tropical Pacific atmospheric circulation due to anthropogenic forcing. Nature 441, 73-76 (2006)

22. Durack, P., Wijffels, S. \& Matear, R. J. Ocean salinities reveal strong global water cycle intensification during 1950-2000. Science 336, 455-458 (2012).

23. Chou, C. \& Neelin, J. D. Mechanisms of global warming impacts on regional tropical precipitation. J. Clim. 17, 2688-2701 (2004).

24. Chou, C., Neelin, J. D., Chen, C.-A. \& Tu, J.-Y. Evaluating the "rich-get-richer" mechanism in tropical precipitation change under global warming. J. Clim. 22, 1982-2005 (2009).

25. He, C. \& Li, T. Does global warming amplify interannual climate variability? Clim. Dyn. 52, 2667-2684 (2019).

26. Giannini, A., Biasutti, M. \& Verstraete, M. M. A climate model-based review of drought in the Sahel: desertification, the re-greening and climate change. Glob. Planet. Change 64, 119-128 (2008).

27. Pendergrass, A. G., Knutti, R., Lehner, F., Deser, C. \& Sanderson, B. M. Precipitation variability increases in a warmer climate. Sci. Rep. 7, 17966 (2017).

28. Biasutti, M. Rainfall trends in the African Sahel: characteristics, processes, and causes. WIREs Clim. Change 10, e591 (2019).

29. Rind, D., Goldberg, R. \& Ruedy, R. Change in climate variability in the 21 st century. Climatic Change 14, 5-37 (1989).

30. Mearns, L. O., Giorgi, F., McDaniel, L. \& Shields, C. Analysis of daily variability of precipitation in a nested regional climate model: comparison with observations and doubled CO2 results. Glob. Planet. Change 10, 55-78 (1995).

31. Räisänen, J. $\mathrm{CO}_{2}$-induced changes in interannual temperature and precipitation variability in 19 CMIP2 experiments. J. Clim. 15, 2395-2411 (2002).

32. Giorgi, F. \& Bi, X. Regional changes in surface climate interannual variability for the 21 st century from ensembles of global model simulations. Geophys. Res. Lett. 32, 1-5 (2005).

33. Hsu, P. C., Li, T., Murakami, H. \& Kitoh, A. Future change of the global monsoon revealed from 19 CMIP5 models. J. Geophys. Res. Atmos. 118, 1247-1260 (2013).

34. Kent, C., Chadwick, R. \& Rowell, D. P. Understanding uncertainties in future projections of seasonal tropical precipitation. J. Clim. 28, 4390-4413 (2015)

35. Collins, M. et al. In Climate Change 2013: The Physical Science Basis (eds. T. F. Stocker et al.) (Cambridge Univ. Press, Cambridge, 2013) pp. 1029-1136.

36. Hegerl, G. C. et al. Challenges in quantifying changes in the global water cycle. Bull. Am. Meteorol. Soc. 96, 1097-1115 (2015).

37. Brown, J. R., Moise, A. F., Colman, R. A. Projected increases in daily to decadal variability of Asian-Australian monsoon rainfall. Geophys. Res. Lett. https://doi.org/ 10.1002/2017GL073217 (2017).

38. Menon, A., Levermann, A., Schewe, J., Lehmann, J. \& Frieler, K. Consistent increase in Indian monsoon rainfall and its variability across CMIP-5 models. Earth Syst. Dyn. 4, 987-300 (2013).

39. Gómara, l. et al. Impact of dynamical regionalization on precipitation biases and teleconnections over West Africa. Clim. Dyn. 50, 4481-4506 (2018).

40. Katz, R. \& Brown, B. Extreme events in a changing climate: Variability is more important than averages. Clim. Change 21, 303-315 (1992).

41. Akinsanola, A. A. \& Zhou, W. Projection of West African summer monsoon rainfall in dynamically downscaled CMIP5 models. Clim. Dyn. 53, 81 (2019).
42. Biasutti, M. Forced Sahel rainfall trends in the CMIP5 archive. J. Geophys. Res. Atmos. 118, 1613-1623 (2013).

43. Gaetani, M. et al. West African monsoon dynamics and precipitation: the competition between global SST warming and $\mathrm{CO}_{2}$ increase in CMIP5 idealized simulations. Clim. Dyn. 48, 1353-1373 (2017).

44. Akinsanola, A. A. \& Zhou, W. Ensemble-based CMIP5 simulations of West African summer monsoon rainfall: current climate and future changes. Theor. Appl. Climatol. 136, 1021-1031 (2019).

45. Monerie, P., Sanchez-Gomez, E. \& Boé, J. On the range of future Sahel precipitation projections and the selection of a sub-sample of CMIP5 models for impact studies. Clim. Dyn. 48, 2751-2770 (2017).

46. Dieterich, $\mathrm{C}$. et al. Evaluation of the SMHI coupled atmosphere-ice ocean model RCA4 NEMO. Rep. Oceanogr. 47, 80 (2013).

47. Panitz, H. J., Dosio, A., Büchner, M., Lïthi, D. \& Keuler, K. COSMO-CLM (CCLM) climate simulations over CORDEX-Africa domain: analysis of the ERA-Interim driven simulations at 0.44 and 0.22 resolution. Clim. Dyn. 1-24 (2014).

48. Pinto, I. et al. Evaluation and projections of extreme precipitation over southern Africa from two CORDEX models. Clim. Change. 42, 3015-3018. https://doi.org/ 10.1007/s10584-015-1573-1 (2014).

49. Moss, R. H. et al. The next generation of scenarios for climate change research and assessment. Nature 463, 747-756 (2010).

50. van Vuuren, D. P. et al. The representative concentration pathways: an overview Clim. Change 109, 5-31 (2011).

51. Huffman, G. J. \& Bolvin, D. T. Version 1.2 GPCP one-degree daily precipitation data set documentation. GPCP. ftp://rsd.gsfc.nasa.gov/pub/1dd-v1.2/1DD_v1.2_doc. pdf (2013).

52. Huffman, G. et al. The TRMM multisatellite precipitation analysis (TMPA): quasiglobal, multiyear, combined-sensor precipitation estimates at fine scales. J. Hydrometeorol. 8, 38-55 (2007).

53. Akinsanola, A. A. et al. Comparison of five gridded precipitation products at climatological scales over West Africa. Meteorol. Atmos. Phys. 129, 669 (2016).

54. Nikulin, G. et al. Precipitation climatology in an ensemble of CORDEX-Africa regional climate simulations. J. Clim. 25, 6057-6078 (2012).

55. Sylla, M., Giorgi, F., Coppola, E. \& Mariotti, L. Uncertainties in daily rainfall over Africa: assessment of gridded observation products and evaluation of a regional climate model simulation. Int. J. Climatol. 33, 1805-1817 (2013).

56. Sillmann, J., Kharin, V., Zwiers, F., Zhang, X. \& Bronaugh, D. Climate extremes indices in the CMIP5 multimodel ensemble: Part 2. Future climate projections. J. Geophys. Res. Atmos. 118, 2473-2493 (2013).

57. Dosio, A., Panitz, H. J., Schubert-Frisius, M. \& Lüthi, D. Dynamical downscaling of CMIP5 global circulation models over CORDEX-Africa with COSMO-CLM: Evaluation over the present climate and analysis of the added value. Clim. Dyn. 44 2637-2661 (2015).

58. Sokol Jurković, R. \& Pasarić, Z. Spatial variability of annual precipitation using globally gridded data sets from 1951 to 2000. Int. J. Climatol. 33, 690-698 (2013).

59. Giorgi, F. \& Bi, X. Regional changes in surface climate interannual variability for the 21 st century from ensembles of global model simulations. Geophys. Res. Lett. 32, L13701 (2005).

60. Akinsanola, A. A. \& Zhou, W. Understanding the variability of West African summer monsoon rainfall: Contrasting tropospheric features and monsoon index. Atmosphere 11, 309 (2020).

61. Allan, R. P. \& Soden, B. J. Atmospheric warming and the amplification of precipitation extremes. Science 321, 1481-1484 (2008).

62. The NCAR Command Language (Version 6.4.0) [Software]. Boulder, Colorado: UCAR/NCAR/CISL/TDD. https://doi.org/10.5065/D6WD3XH5 (2017).

\section{ACKNOWLEDGEMENTS}

This work was supported by the National Natural Science Foundation of China Grant (41675062). N.K. was supported by EU H2020 TRIATLAS (grant 817578) and ERC STERCP (grant 648982) projects. The Bjerknes Climate Prediction Unit supported AAA visit to the University of Bergen (Trond Mohn Foundation grant BFS2018TMT01). We are thankful to Dr. Angeline Pendergrass of National Center for Atmospheric Research, Dr. Josephine Brown of the University of Melbourne, and Dr. Gabriel J. Kooperman of the University of Georgia, for their helpful advice and comments. We also appreciate WCRP and START for setting up and funding the CORDEX-Africa analysis initiative, and the University of Cape Town for leading the training and analysis program. We are very grateful to the regional downscaling group who kindly shared the downscaled data used in this analysis. We are also grateful to the services that have operated the GPCP and TRMM datasets. We thank the anonymous reviewers for their constructive comments and suggestions. 


\section{AUTHOR CONTRIBUTIONS}

A.A.A. and W.Z. designed the research, led the data collection, performed the data analysis, and drafted the manuscript with suggestions and comments from T.Z. and N.K. All co-authors contributed to scientific interpretations and helped improve the manuscript.

\section{COMPETING INTERESTS}

The authors declare no competing interests.

\section{ADDITIONAL INFORMATION}

Supplementary information is available for this paper at https://doi.org/10.1038/ s41612-020-0125-1.

Correspondence and requests for materials should be addressed to W.Z.

Reprints and permission information is available at http://www.nature.com/ reprints
Publisher's note Springer Nature remains neutral with regard to jurisdictional claims in published maps and institutional affiliations.

Open Access This article is licensed under a Creative Commons Attribution 4.0 International License, which permits use, sharing, adaptation, distribution and reproduction in any medium or format, as long as you give appropriate credit to the original author(s) and the source, provide a link to the Creative Commons license, and indicate if changes were made. The images or other third party material in this article are included in the article's Creative Commons license, unless indicated otherwise in a credit line to the material. If material is not included in the article's Creative Commons license and your intended use is not permitted by statutory regulation or exceeds the permitted use, you will need to obtain permission directly from the copyright holder. To view a copy of this license, visit http://creativecommons. org/licenses/by/4.0/.

(c) The Author(s) 2020 